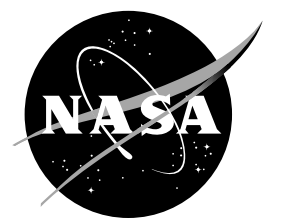

\title{
Modeling and Development of a Magnetic Bearing Controller for a High Speed Flywheel System
}

Timothy P. Dever

QSS Group, Inc., Cleveland, Ohio

Gerald V. Brown

Glenn Research Center, Cleveland, Ohio

Kirsten P. Duffy and Ralph H. Jansen

University of Toledo, Toledo, Ohio 
Since its founding, NASA has been dedicated to the advancement of aeronautics and space science. The NASA Scientific and Technical Information (STI) Program Office plays a key part in helping NASA maintain this important role.

The NASA STI Program Office is operated by Langley Research Center, the Lead Center for NASA's scientific and technical information. The NASA STI Program Office provides access to the NASA STI Database, the largest collection of aeronautical and space science STI in the world. The Program Office is also NASA's institutional mechanism for disseminating the results of its research and development activities. These results are published by NASA in the NASA STI Report Series, which includes the following report types:

- $\quad$ TECHNICAL PUBLICATION. Reports of completed research or a major significant phase of research that present the results of NASA programs and include extensive data or theoretical analysis. Includes compilations of significant scientific and technical data and information deemed to be of continuing reference value. NASA's counterpart of peerreviewed formal professional papers but has less stringent limitations on manuscript length and extent of graphic presentations.

- TECHNICAL MEMORANDUM. Scientific and technical findings that are preliminary or of specialized interest, e.g., quick release reports, working papers, and bibliographies that contain minimal annotation. Does not contain extensive analysis.

- CONTRACTOR REPORT. Scientific and technical findings by NASA-sponsored contractors and grantees.
- CONFERENCE PUBLICATION. Collected papers from scientific and technical conferences, symposia, seminars, or other meetings sponsored or cosponsored by NASA.

- SPECIAL PUBLICATION. Scientific, technical, or historical information from NASA programs, projects, and missions, often concerned with subjects having substantial public interest.

- TECHNICAL TRANSLATION. Englishlanguage translations of foreign scientific and technical material pertinent to NASA's mission.

Specialized services that complement the STI Program Office's diverse offerings include creating custom thesauri, building customized databases, organizing and publishing research results ... even providing videos.

For more information about the NASA STI Program Office, see the following:

- Access the NASA STI Program Home Page at http://www.sti.nasa.gov

- E-mail your question via the Internet to help@sti.nasa.gov

- Fax your question to the NASA Access Help Desk at 301-621-0134

- Telephone the NASA Access Help Desk at 301-621-0390

- Write to:

NASA Access Help Desk

NASA Center for AeroSpace Information 7121 Standard Drive

Hanover, MD 21076 
NASA/TM-2005-213877

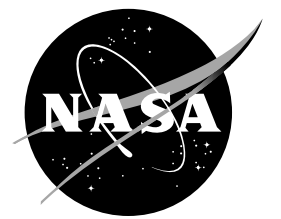

\section{Modeling and Development of a Magnetic Bearing Controller for a High Speed Flywheel System}

Timothy P. Dever

QSS Group, Inc., Cleveland, Ohio

Gerald V. Brown

Glenn Research Center, Cleveland, Ohio

Kirsten P. Duffy and Ralph H. Jansen

University of Toledo, Toledo, Ohio

Prepared for the

Second International Energy Conversion Engineering Conference sponsored by the American Institute of Aeronautics and Astronautics Providence, Rhode Island, August 16-19, 2004

National Aeronautics and

Space Administration

Glenn Research Center 
Available from

NASA Center for Aerospace Information 7121 Standard Drive

Hanover, MD 21076
National Technical Information Service 5285 Port Royal Road Springfield, VA 22100

Available electronically at http://gltrs.grc.nasa.gov 


\title{
Modeling and Development of a Magnetic Bearing Controller for a High Speed Flywheel System
}

\author{
Timothy P. Dever \\ QSS Group, Inc. \\ Cleveland, Ohio 44135 \\ Gerald V. Brown \\ National Aeronautics and Space Administration \\ Glenn Research Center \\ Cleveland, Ohio 44135 \\ Kirsten P. Duffy and Ralph H. Jansen \\ University of Toledo \\ Toledo, Ohio 43606
}

\begin{abstract}
This paper describes a modeling effort used to develop an improved type of magnetic bearing controller, called a modal controller, for use on high speed flywheel systems. The controller design is based on models of the flywheel system, is designed to directly control the natural dynamics of the spinning rotor, and is generic enough to be readily adapted to future flywheel systems. Modeling and development are described for two key controller subsystems: the modal controller subsystem, which allows direct control over the rotor rigid body modes, and the bending mode compensation subsystem, which tracks, and prevents interference from, the rotor bending modes during flywheel operation. Integration of modeling results into the final controller is described and data taken on the NASA Glenn D1 flywheel module during high speed operation are presented and discussed. The improved modal controller described in this paper has been successfully developed and implemented and has been used for regular hands-free operation of the D1 flywheel module up to its maximum operating speed of $60,000 \mathrm{rpm}$.
\end{abstract}

\section{Nomenclature}

$F_{X 2} \quad$ Force applied by the controller in the combo X direction (lb)

$I_{P} \quad$ Rotor polar moment of inertia (lb-in-s $\left.{ }^{2}\right)$

$I_{T} \quad$ Rotor moment of inertia about the center of mass (CM) (lb-in-s ${ }^{2}$ )

$I_{T r} \quad$ Moment of inertia about the radial magnetic bearing (MB) (lb-in-s ${ }^{2}$ )

$K_{n \times 2} \quad$ Negative stiffness of the combo MB in the x-dir (lb/in)

$K_{i x 2} \quad$ Current stiffness of the combo MB in the x-dir (lb/A)

$K \quad$ Combined gain of sensor system, signal conditioning, and PWM

$K_{p x 2} \quad$ Proportional gain of the combo MB in the X direction

$m \quad$ Flywheel mass (lb-s ${ }^{2} /$ in)

$X 1, Y 1 \quad$ radial end bearing and sensor axes

$X 2, Y 2, Z$ combo end bearing and sensor axes

$Z_{b 2} \quad$ Distance in Z-dir from CM to combo MB (in)

$Z_{b 1} \quad$ Distance in $\mathrm{Z}$-dir from $\mathrm{CM}$ to radial MB (negative) (in)

$Z_{s 2} \quad$ Distance in z-dir from CM to combo sensor (in)

$\alpha \quad$ Angular displacement about the y-axis (rad)

$\omega_{x 2} \quad$ Natural frequency of the flywheel at the combo MB about the $\mathrm{x}$-direction $(\mathrm{rad} / \mathrm{s})$

\section{Introduction}

High-speed flywheel systems are being developed at NASA Glenn Research Center (GRC) in Cleveland, Ohio. Flywheels show promise as an alternative to batteries and reaction wheels for space systems. Strengths of this technology include high energy density, long life, capability for up to 90 percent depth of discharge, and peaking or pulse power capability. Flywheels can also be deployed in an array which provides both energy storage and attitude 
control. A system level flywheel test bed is operational at GRC. The flywheel system utilizes active magnetic bearings (MB) to provide a long-life, low-loss suspension of the rotating mass. The MB control system commands power amplifiers, which produce current in the bearing actuators; forces produced by the actuators suspend the rotor. The system utilizes a feedback loop in which the position of the rotor is measured with eddy current sensors and used as the input to the MB control algorithm. The flywheel modules use a motor/generator coaxial with the rotor to facilitate energy storage and retrieval. A system level flywheel test bed called the High Energy Flywheel Facility (HEFF) is operational at GRC; the flywheel module under test is called the D1 module.

This paper describes a modeling effort which was used to develop an improved type of MB controller. The goals of this effort were to develop a controller which is based on models of the flywheel module and controller, is designed to directly control the natural dynamics of the spinning rotor, and is generic enough to be readily adapted to future flywheel systems. This paper focuses on development of two key portions of this improved controller: the modal control section, and bending mode compensation. Integration of modeling results into the final controller is described, and data taken on the D1 module during high speed operation is presented and discussed.

The improved modal controller described in this paper has been successfully developed and implemented, and used for regular hands-free operation of the D1 flywheel up to its maximum operating speed of 60,000 rpm.

\section{Problem Statement}

The GRC flywheel team has developed successful MB controllers for its first few flywheel modules by building custom controllers for each module. Although this approach works, it has several problems: the custom approach is time consuming, the resultant MB controllers are not easily portable to new module designs, and, since the approach is not model-based, the resulting controller does not necessarily provide the most stable architecture. Also, as of this writing, several new flywheel module designs are underway, each featuring design improvements over previous modules (e.g., higher energy density and redundant radial MB axes). The goal of this model-based MB controller development is to address the above problems, and develop an improved MB controller which will provide better controller performance, quicker design cycle time, and portability to new flywheel modules. Specifically, the goals of this effort are to develop a new controller which is:

1. Model-based

2. Developed considering flywheel rotordynamic modes

3. Generic and portable to new flywheel modules

In order to meet goal 1, a model is developed for the module and the controller, based on measurable system characteristics (properties of flywheel rotor, MB actuator, and MB controller). This model is validated through testing, and then the relevant model parameters are incorporated into the final controller.

The natural dynamics of the spinning rotor must be considered while deciding on the controller approach in order to meet goal 2. Simulations run on the flywheel model demonstrate that the rotordynamic behavior is dominated by its rigid body modes. Thus, a new controller type called a modal controller was developed, to allow direct control of these rigid body modes during flywheel operation.

In order to meet goal 3, the MB controller was designed with portability in mind. All of the measurable system parameters (e.g., rotor parameters such as Ip, It and mass, module parameters such as $Z_{b 2}$ and $Z_{s 2}$, and system parameters such as $\mathrm{K}$ ) are included in setup files, instead of imbedded in the control code, as with previous controllers. Setting the system up with these generic variables improves controller portability and decreases ramp-up time required for levitation and full speed operation of a new model flywheel module.

\section{System Model Development}

In this section, a model for the flywheel system (module and controller) is developed and validated. Measured parameter values will be used directly in the new controller, and the results of the analysis will lead to selection of the modal approach for the controller (next section).

\section{A. D1 Module Configuration}

The D1 flywheel and motor-generator are mounted on the same shaft. A five axis control system is used to levitate the rotor (fig. 1). Shaft location on each of the five axes is determined by the controller using non-contact eddy current sensors. The radial axes, for the sensors as well as the MBs, are defined as X1 and Y1 (bottom radial plane) and $\mathrm{X} 2$ and $\mathrm{Y} 2$ (top radial plane). Note that the sensors and actuators are offset from each other; this is an important consideration for $\mathrm{MB}$ controller implementation. The $\mathrm{Z}$ axis describes axial motion and sensing; the $\mathrm{Z}$ 
sensor is at the top of the module, and the axial motion is generated by the combo bearing, so-called because it generates radial as well as axial forces.

In addition to axial and radial sensors, the system also has a "once around" (OAR) sensor at the top of the module, which is used to generate angular position and speed information for use in the controller, and a shaft growth sensor, used to ensure rotor heating does not cause excessive shaft growth.

Although each of the five MBs does contain permanent magnets, used to generate bias flux, all five axes use active MBs. When MB power is off, the rotor rests on rolling element backup bearings, which are located at the top and bottom of the module.

A simplified schematic of one axis of the MB control loop is shown schematically in figure 2 . The bearing control code in the MB controller generates command signals which provide shaft levitation.

The PWM amplifier section converts these command signals to drive currents using pulse width modulated (PWM) amplifiers, then filters the currents. These currents are fed to the MB actuators, which

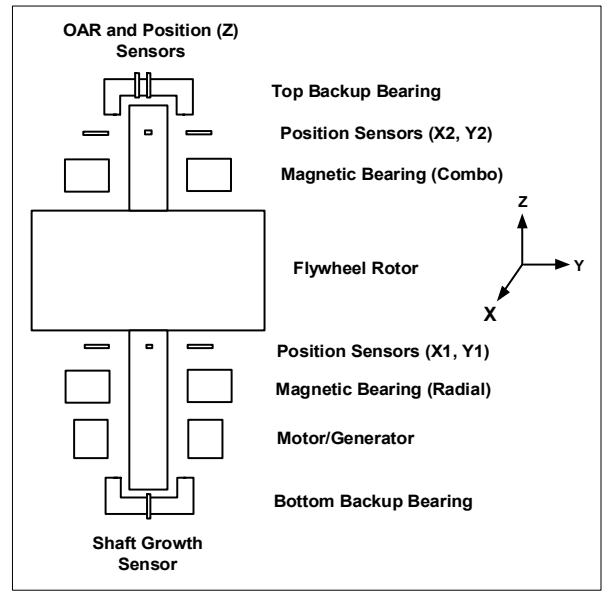

Figure 1.-D1 flywheel module schematic. generate forces to suspend the rotor. The rotor position is measured using non-contact eddy current sensors. Signals from the sensors are then processed by the signal conditioning system, and fed back to the bearing controller as inputs to the MB control algorithm.

\section{B. Decentralized PD Controller}

A very simple $\mathrm{MB}$ controller called a decentralized PD controller (d-PD controller) is now developed for test purposes; this controller looks quite a bit like the simplified schematic presented in figure 2. The d-PD controller can be built by setting up a control system consisting of five separate PD

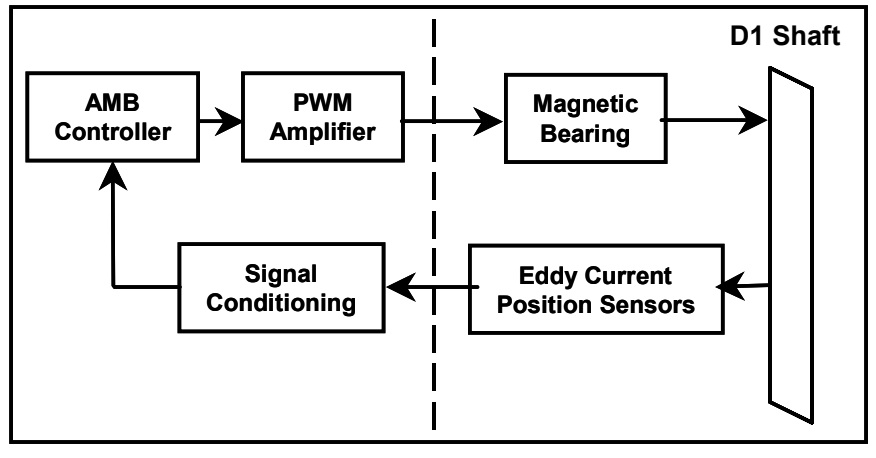

Figure 2.-Simplified schematic of MB control system. control loops: each of the five loops uses the sensors from a single axis as its input signal, and sends control signals to the MB actuator for that same axis as its output signal. This is called a decentralized system because each PD controller considers its own axis only, and has no information on any other axis in the system. Although rough approximations are used in the d-PD controller for the radial application (e.g., the incorrect assumption that sensors and actuators for each axis are co-located), levitation and low speed operation of the rotor for testing purposes is possible using this type of controller. Note that, although the d-PD controller is inadequate for use in the radial MB controller, due to the inherently simpler dynamics of the axial levitation, the d-PD is sufficient for axial control to full rotor speed.

\section{System Modeling}

In order to generate the flywheel system model, measurements need to be made for each of the key system processes described in figure 2. Once all measurements were made, models of the key processes were built into a complete system model, within a commercially available simulation package.

The key processes which need to be modeled are:

1. MB Controller

2. PWM amplifier/filters

3. Flywheel rotor

4. Eddy current sensor system

5. Sensor signal conditioning

6. MB actuator

Details of these measurements are as follows: 
A simple d-PD controller was selected and implemented to levitate the rotor during the modeling measurements. Modeling of this testing d-PD controller was straightforward; the d-PD control algorithm was simply transferred into the system model.

Modeling of the PWM amplifier and filter was accomplished by performing a transfer function across the PWM and filter system while the flywheel was levitated. A model of this transfer function was then input into the system model.

Next, a first principles model of an idealized flywheel rotor was developed. The free body diagram (FBD) of this idealized rotor, consisting of a cylindrical rotor on springs, is shown in figure 3. Note that this model assumes a rigid rotor; i.e., a simplifying assumption that the rotor has no bending modes is made. Using this FBD and known flywheel rotor characteristics (e.g., rotor mass and polar and transverse moments of inertia), a mathematical model of this idealized rotor was developed (ref. 1). This mathematical model was then included in the system model.

Models of the eddy current sensor system and the sensor signal conditioning were straightforward. The specifications from the sensor system manufacturer contained sufficient information to build a model, and, since the sensor signal conditioning was designed and built in-house, mathematical representation of this subsystem's transfer function was straightforward.

This completes our system model, except for the model of the MB actuator. The two crucial properties which need to be measured on the radial actuators are the negative stiffnesses and current stiffnesses. Measurement of these properties was more complicated than the above; these properties are defined, and the measurement process is explained, in the next section.

\section{MB Actuator Properties}

MB actuator current stiffness is a measure of the force generated by the bearing given an input current. Current stiffness is designated as $\mathrm{Ki}$, and its units are in $\mathrm{Lb} / \mathrm{A}$. Knowledge of each MB actuator's Ki is critical for proper scaling of the controller output values.

Each MB actuator contains permanent magnets (PMs), which are used to provide a bias field; these PMs cause the MB

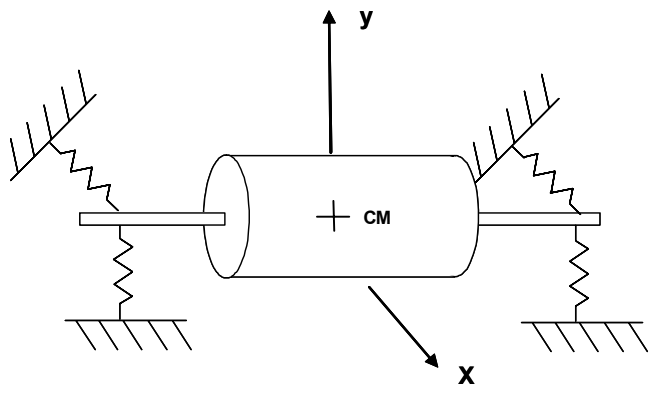

Figure 3.-Schematic of idealized rotor.
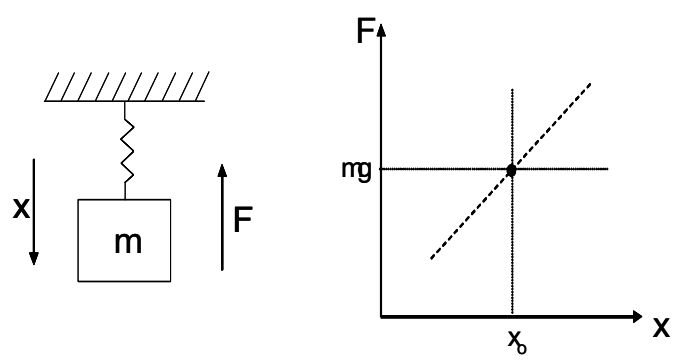

Figure 4.-Positive stiffness, spring.
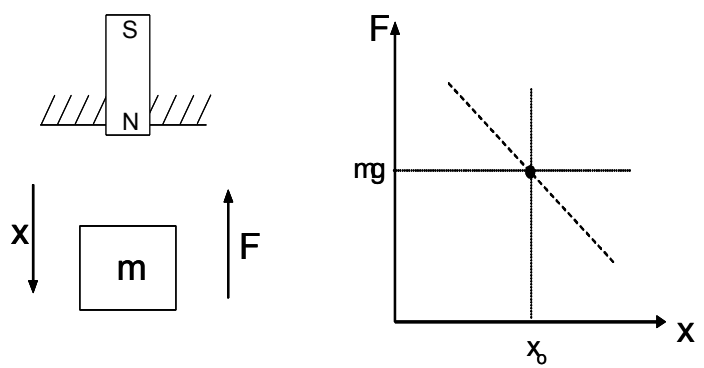

Figure 5.-Negative stiffness, permanent magnet. actuators to have an inherent negative stiffness. Negative stiffness is designated as $\mathrm{Kn}$, and its units are $\mathrm{Lb} / \mathrm{in} . \mathrm{Kn}$ is easily defined by first considering standard spring stiffness.

In the mass-spring system shown in figure 4 , the mass will nominally come to rest at position $\mathrm{x}_{0}$, where the spring force $\mathrm{F}$ is equal to the force on the mass due to gravity, $\mathrm{mg}$. When the mass is pulled in the positive $\mathrm{x}$ direction, the spring will generate increased force, and when the mass is moved in the negative $\mathrm{x}$ direction, the spring will generate less force. Plotting this force response generates a line which describes the (positive) spring stiffness.

Now consider a ferromagnetic mass in the presence of a PM (fig. 5). As the mass moves in the positive direction, the attractive force from the PM is reduced, while motion in the negative direction increases the attractive force. For small displacements (a realistic assumption in the D1 MB actuators - backup bearings limit motion to \pm 7 mils) this motion is roughly linear, and the characteristic stiffness has opposite sign to the spring stiffness, hence the name "negative stiffness."

Knowledge of each MB actuator's Ki and Kn values is required in order to complete the flywheel system model and the final MB controller. Unfortunately, direct measurement of the Ki and Kn values is very difficult; in order to facilitate these measurements, an indirect measurement technique had to be developed, using the d-PD controller.

The first step in measuring $\mathrm{Ki}$ and $\mathrm{Kn}$ values is to measure the rotor's natural frequency at each radial MB actuator, over a range of stiffnesses. While levitated on the d-PD type controller, the net stiffness of any of the five 
MB axes (where net stiffness equals stiffness from PD controller plus negative stiffness) is proportional to the natural frequency of the axis squared, and it can be measured by reducing the damping of the axis under test until the rotor oscillates (ref. 2). While levitated at $0 \mathrm{rpm}$ on the d-PD controller, these natural frequencies were measured for all five axes of the D1 module, at multiple proportional gain values, and the relationship between MB frequency and the controller stiffness was generated for each of the axes. A plot of the combo $\mathrm{x}$ axis actuator ("X2") data for natural frequency (in $\mathrm{Hz}$ ) versus combo MB controller stiffness $K_{p x z}$ is shown in figure 6 .

In order to calculate the actuator $\mathrm{Ki}$ and $\mathrm{Kn}$ values from the frequency data, a relationship between the frequency data and the $\mathrm{Ki}$ and $\mathrm{Kn}$ values must be

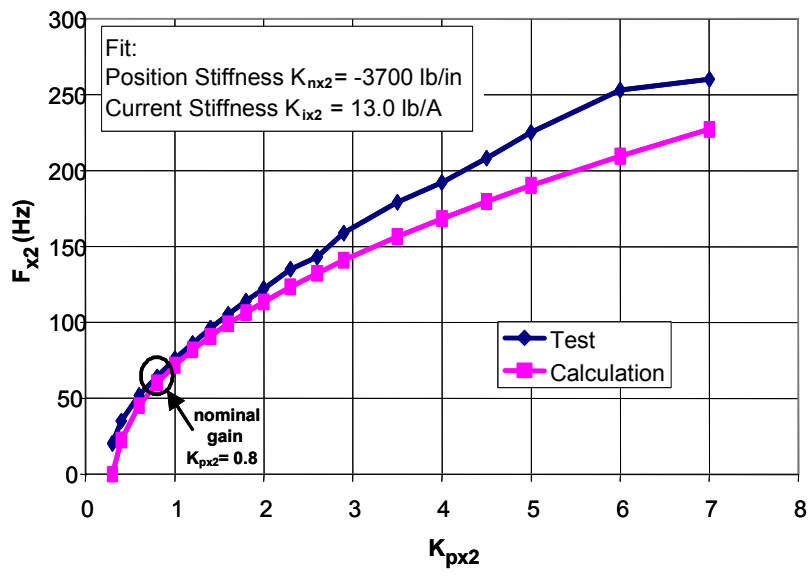

Figure 6.-D1 frequency versus keyboard stiffness-X2. developed. A FBD of the rotor for use in this derivation is shown in figure 7. During the frequency measurements, only one axis was allowed to oscillate; accordingly, the FBD (which depicts the combo $\mathrm{x}$ axis, X2, under test), models the radial end MB actuator, $\mathrm{X} 1$, as a hinge, and assumes no allowed motion in the $\mathrm{Y}$ direction. Thus, the forces acting on the flywheel include the applied controller force on the flywheel in the X2 direction $\left(F_{X 2}\right)$, the negative stiffness in that direction $\left(K_{n \times 2}\right)$, and gravity at the CM. The equation of motion for this system is:

$$
I_{T r} \ddot{\alpha}=\sum M_{y}
$$

where $\Sigma M_{y}$ is the sum of the moments about the y-axis at the radial MB and $I_{T r}$ is the moment of inertia about the origin $\left(I_{T r}=I_{T}+m Z_{b 1}{ }^{2}\right.$, where $I_{T}$ is the moment of inertia about the center of mass).

Considering this, the equation of motion now becomes

$$
\left(I_{T}+m Z_{b 1}^{2}\right) \ddot{\alpha}=-m g Z_{b 1} \alpha-K_{n x 2}\left(Z_{b 2}-Z_{b 1}\right)^{2} \alpha-F_{x 2}\left(Z_{b 2}-Z_{b 1}\right) .
$$

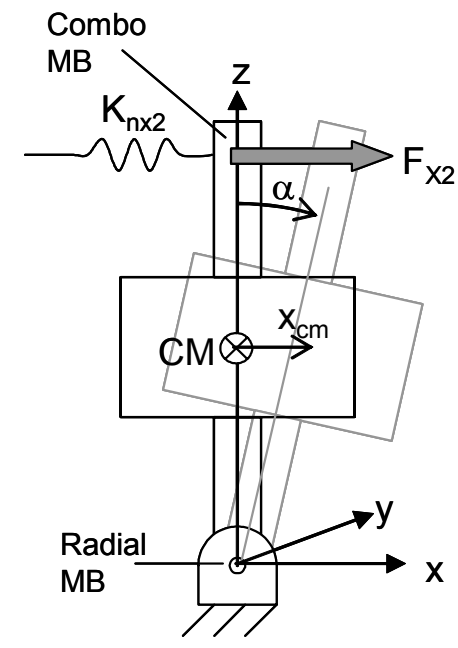

Figure 7.- $\mathrm{Ki}$ and $\mathrm{Kn}$ calculation.

The angle $\alpha$ is related to the center of mass displacement $\mathrm{x}_{c m}$ such that

$$
\mathrm{x}_{c m}=-Z_{b 1} \alpha,
$$

and, assuming no derivative gain, the controller force $F_{x 2}$ is

$$
F_{x 2}=K_{i x 2} K_{p x 2} K\left(\frac{Z_{s 2}-Z_{b 1}}{Z_{b 1}}\right) x_{c m}
$$

Incorporating the above two relationships into the equation of motion gives us

$$
\left(I_{T}+m Z_{b 1}^{2}\right) \ddot{x}_{c m}=\left[-m g Z_{b 1}-K_{n x 2}\left(Z_{b 2}-Z_{b 1}\right)^{2}-K_{i x 2} K_{p x 2} K\left(Z_{b 2}-Z_{b 1}\right)\left(Z_{s 2}-Z_{b 1}\right)\right] x_{c m} .
$$

This yields a natural frequency $\omega_{\mathrm{x} 2}$ that is a function of the negative stiffness $K_{n \times 2}$, the current stiffness $K_{i x 2}$, and the proportional gain $K_{p x 2}$ :

$$
\omega_{x 2}^{2}=\frac{m g Z_{b 1}+K_{n x 2}\left(Z_{b 2}-Z_{b 1}\right)^{2}+\left(Z_{b 2}-Z_{b 1}\right)\left(Z_{s 2}-Z_{b 1}\right) K_{i x 2} K_{p x 2} K}{I_{T}+m Z_{r}^{2}} .
$$


More simply, this equation can be written as

$$
\omega_{x 2}^{2}=f_{\text {slope }}\left(K_{i x 2}\right) \times K_{p x 2}+f_{\text {int }}\left(K_{n x 2}\right),
$$

where the intercept is a linear function of the negative stiffness, $K_{n \times 2}$,

$$
f_{\text {int }}=\frac{m g Z_{b 1}+\boldsymbol{K}_{\boldsymbol{n} \boldsymbol{x} 2}\left(Z_{b 2}-Z_{b 1}\right)^{2}}{I_{T}+m Z_{b 1}^{2}},
$$

and the slope is a linear function of the current stiffness, $K_{i x 2}$ :

$$
f_{\text {slope }}=\frac{\left(Z_{b 2}-Z_{b 1}\right)\left(Z_{s 2}-Z_{b 1}\right) \boldsymbol{K}_{\boldsymbol{i x} 2} K}{I_{T}+m Z_{b 1}^{2}}
$$

The above two equations form the desired relationship between the experimentally determined natural frequency data and the Ki and $\mathrm{Kn}$ values for the MB actuator under test. When the frequency data $\left(\omega_{\mathrm{x} 2}^{2}\right.$ versus $\left.\mathrm{K}_{x 2}\right)$ is plotted as a line, the slope will be $f_{\text {slope }}$ and the intercept $f_{\text {int }}$. Since all other parameters in the above equations have been measured, $\mathrm{K}_{n x 2}$ and $\mathrm{K}_{i x 2}$ can then be estimated from this plot.

Using the process developed above, the negative stiffness and current stiffness for each of the radial MB actuators was calculated. The results are presented in table 1.

Once $\mathrm{Ki}$ and $\mathrm{Kn}$ measurements were made, the system model was complete. Next, validation runs of $0 \mathrm{rpm}$ test step functions on the D1 module under d-PD control were performed, and compared to simulations on the system model. Sufficient agreement between the system model simulations and experimental data confirmed correct measurement of the actuator $\mathrm{Ki}$ and $\mathrm{Kn}$ values, and constituted validation of the system model for the $0 \mathrm{rpm}$ test case.

TABLE 1.-RADIAL BEARING STIFFNESSES
\begin{tabular}{|l|l|}
\hline \multicolumn{1}{|c|}{ Stiffness } & \multicolumn{1}{c|}{ Value } \\
\hline Kn2 (2-plane negative stiffness) & $-3700 \mathrm{Lb} / \mathrm{in}$ \\
\hline Ki2 (2-plane current stiffness) & $13 \mathrm{Lb} / \mathrm{A}$ \\
\hline Kn1 (1-plane negative stiffness) & $-8500 \mathrm{Lb} / \mathrm{in}$ \\
\hline Kil (1-plane current stiffness) & $10 \mathrm{Lb} / \mathrm{A}$ \\
\hline
\end{tabular}

The measured $\mathrm{Ki}$ and $\mathrm{Kn}$ values were then incorporated directly into the controller. The $\mathrm{Ki}$ values are used at the output of the controller, to correctly scale MB command signals for output to the PWMs, while the Kn values are used to compensate for the MB negative stiffness in the modal controller development (below).

\section{Modal Controller Development}

Thus far, the controller meets two of the three main goals specified in the problem statement: the controller is model based, and it has been designed to be generic and portable. However, we do not yet have a controller which is designed to directly affect the natural rotordynamics, which leaves goal 2 unsatisfied. In this section, we develop a controller which meets goal 2 .

First, the rotordynamics of the D1 rotor are studied, with a first principles model of the rotor over the flywheel operating speed range; this simulation demonstrates the behavior of the rotor rigid body modes. Based on these results, a modal controller, so called because it directly controls the rigid body modes of the rotor, is developed. Since the modal controller is designed to directly impact the rotor natural dynamics, it satisfies goal 2 of the problem statement.

Next, implementation and testing of the modal controller on the D1 is performed, and experimental data is presented.

\section{A. Rigid Body Modes and the Modal Controller}

The d-PD controller used thus far in testing does have several benefits: it is very simple to implement, and intuitive to debug and tune. Unfortunately, since the d-PD does not consider plant rotordynamics, it will not provide stable radial control of the rotor at high speeds. 
Ideally, the MB controller must take into account the dynamics of the spinning rotor. In order to understand and quantify the rotordynamics of the D1 rotor, the first principles model of the idealized rotor (fig. 3) was simulated over the designed operating range $(0$ to $60 \mathrm{k}$ rpm). The simulation demonstrates that this rotor type has two natural rigid body modes: the tilt mode and the center of mass $(\mathrm{CM})$ mode. Using the simulation, these rigid body modes were mapped for the rotor operating speed range; results are presented in figure 8 . The tilt and $\mathrm{CM}$ modes are called rigid body modes, because they do not cause rotor bending; instead, they describe the natural motion of a stiff rotor. The tilt mode describes rotor tilt around its center of mass, and the CM mode describes non-tilting motion of the rotor, at the center of mass. These modes are depicted in figure 9. Understanding changes in these mode frequencies with speed is critical, for proper tuning of our new controller.

The model of the rotor shows that there are actually a pair of CM and a pair of tilt modes in the rotor (both CM modes are at the same frequency at $0 \mathrm{rpm}$, as are the tilt mode frequencies), and the frequencies of these CM and tilt modes are a function of the stiffnesses of the springs used to support the ideal rotor. As seen in figure 8, the CM mode frequencies do not change much with rotor speed. However, as the rotor spins, the theoretical tilt mode frequencies do change as a function of rotor speed; in fact, once the rotor is spinning, the tilt modes become whirl modes, which separate with speed into tilt forward whirl (FW) and tilt backward whirl (BW) modes, where FW rotation is in the same direction as rotor rotation, and BW rotation is in the direction opposite rotor rotation. The BW mode frequency decreases with rotor speed, while the FW frequency increases with speed, and theoretically asymptotes to Ip/It times the synchronous speed (1/rev) at high speeds (note that the D1 rotor Ip/It ratio is 0.8 ; in the simulation in figure 8 , the $\mathrm{FW}$ mode reaches $800 \mathrm{~Hz}$ at $60 \mathrm{k} \mathrm{rpm}=1000 \mathrm{~Hz}$ ). The product of the $\mathrm{BW}$ and $\mathrm{FW}$ frequencies, in theory, remains the same at all speeds; thus, the $\mathrm{FW} * \mathrm{BW}$ product, which can be measured at $0 \mathrm{rpm}$, should remain constant through the operating range.

The results of this modeling effort clearly explain why the simple d-PD controller is insufficient as an MB controller-the decentralized proportional and derivative gains of the d-PD controller do not allow us access to the rigid body modes. A new type of controller must be built to do this-the modal controller.

Obviously, our flywheel rotor does not look like the idealized rotor used to develop the idealized model used to map the theoretical rigid body modes; the D1 MB actuator stiffnesses are negative, not positive. Our approach to creating a modal controller is undo these differences; to convert the flywheel rotor in the D1 system into a rotor similar to the idealized rotor, then to make a controller which considers the rigid body modes (natural rotor dynamics).

The first step in "undoing" the nonideal nature of the D1 controller is to cancel the negative stiffness of the MB actuators.

\section{B. Negative Stiffness Cancellation: Free Rotor}

The measured $\mathrm{Kn}$ values for both sets of radial MB actuators are used to cancel the effect of the negative stiffness in the actuators. This is done in the controller by adding an equal and opposite (positive) stiffness to the MB command signal, which counteracts the MB actuator negative stiffness.

Since the radial sensors and actuators are located at different positions along the shaft (see fig. 1), the sensor positions which are input to the controller have to first be converted to reflect the rotor position at the actuators. This is done using coordinate transformations, based on the locations of both actuators and both sets of sensors relative to each other. 
Next, the rotor position at each actuator is multiplied by the opposite sign Kn value for that actuator. This value is then output to the MB actuators as a negative stiffness canceling force.

The net effect of negative stiffness cancellation is that the rotor becomes a "free rotor," unimpacted by negative stiffness, which the modal controller can then be applied to. Now that the negative stiffnesses of each of the actuators has been cancelled, we will add an appropriate positive stiffness (we will add damping, also) which makes the flywheel rotor more closely approximate the idealized rotor presented in figure 3.

\section{Controlling Rigid Body Modes: Modal Controller}

Now that the effects of negative stiffness have been cancelled, the modal controller can be developed. The goal of the modal controller is to allow separate control of the stiffness (thus frequency) and damping of the rotor's rigid body modes.

The first step is to convert the rectilinear sensor inputs $X_{1}, Y_{1}, X_{2}$, and $X_{2}$ into modal coordinates, which describe the coordinates of the rotor in terms of the rigid body modes. The locations of the position sensors and actuators with respect to the rotor center of mass are known, and are used to generate transformation matrices which perform these conversions. Thus, inside of the modal controller, $X_{1}, Y_{1}, X_{2}$, and $Y_{2}$ are converted to $X_{c m}$ and $Y_{c m}$ (the relative location of the rotor center of mass with respect to its centered position) and $X_{\text {tilt }}$ and $Y_{\text {tilt }}$ (the angles that the rotor is tilted about the $\mathrm{Y}$ and $\mathrm{X}$ axes, respectively).

Once the sensor signals have been converted to modal coordinates, separate PD controllers are applied to the sets of modal coordinates. These modal PD outputs are then converted from modal coordinates to rectilinear MB actuator coordinates, and summed with the negative stiffness compensation signal ("NS CMD") to form the MB controller output. A simplified schematic of the modal controller is shown in figure 10.

\section{Verification and Tuning of Modal Controller}

As desired, the separate tilt and CM modal PD controllers developed in the previous section allow independent, direct control of the stiffness and damping of the rotor rigid body modes-modal PD controller proportional gains $\mathrm{Kcm}$ and Ktilt provide control of the rigid body mode stiffnesses (and thus frequencies), and damping of the rigid body modes is controlled by modal PD controller derivative gains $\mathrm{C}_{\mathrm{cm}}$ and $\mathrm{C}_{\text {tillt }}$.

Now that the modal controller has been built, the next step is to verify that we have achieved modal separation. After that, the controller can be tuned.

Due to the complexity of setting up the modal controller (multiple coordinate transformations), we would like to verify that we have achieved modal separation. This can be done by first levitating the rotor on the modal controller, then introducing a step command input into a test plane (for example, the $\mathrm{X}_{1}-\mathrm{X}_{2}$ plane) and dropping the damping of the mode under test. Modal separation can be verified by observing the underdamped response of the rotor position in time. If the modes have been properly separated, the position sensor signals during ring down for the plane under test should be in phase while the CM mode is underdamped, and out of phase while the tilt mode is underdamped. This test was performed, for the $\mathrm{CM}$ and the tilt modes, in both the $\mathrm{X}$ and the $\mathrm{Y}$ planes, and modal separation was verified.

Once modal separation has been verified, tuning can commence. The first step to tuning the modal controller is deciding the desired mode frequencies for the controller; with the modal controller, the $0 \mathrm{rpm} \mathrm{CM}$ and tilt mode frequencies can be set separately.

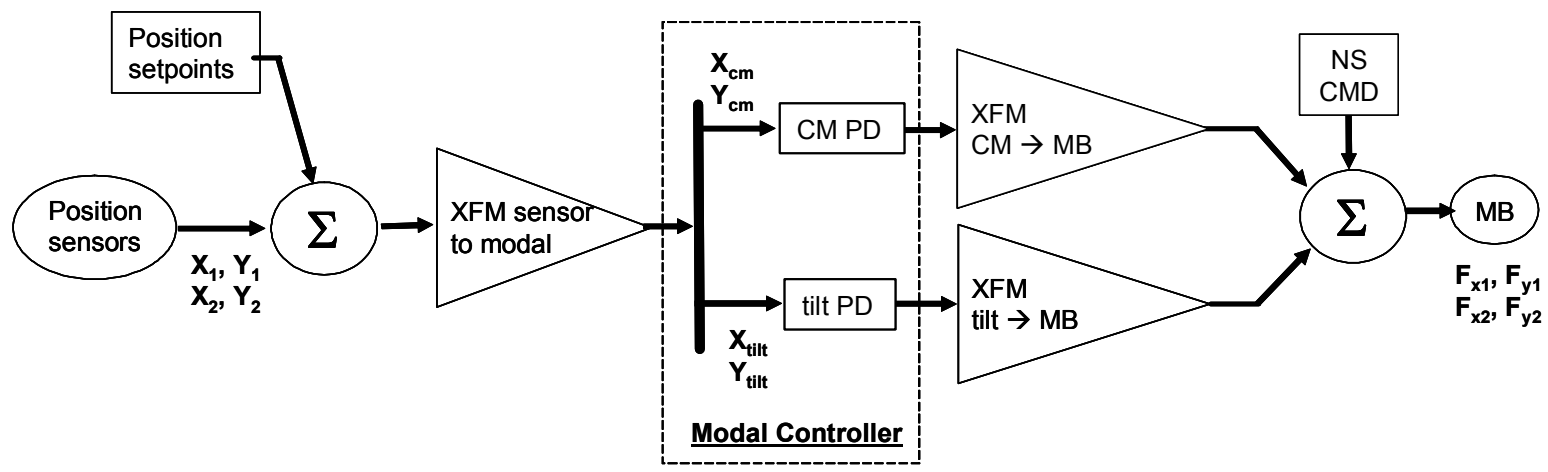

Figure 10.-Schematic of modal controller implementation. 
As was mentioned above, once the rotor is spinning, the $0 \mathrm{rpm}$ tilt modes split into forward whirl (FW) and backward whirl (BW) modes; the BW frequency decreases with rotor speed, while the FW mode frequency increases with speed, theoretically asymptoting to the Ip/It ratio of the rotor at high speeds. Since the Ip/It for the D1 rotor is less than 1 (designed intentionally at 0.8 ), the FW mode will "cross over" the rotor synchronous frequency while the rotor is spinning up. To allow safer operation (minimal impact of interaction between the synchronous and FW mode), we would like this crossover to occur at a relatively low speed. Therefore, the tilt $0 \mathrm{rpm}$ frequency is set to $30 \mathrm{~Hz}$. Note that this also sets the tilt stiffness to a relatively low value; although this may seem counterintuitive, this low tilt stiffness does not negatively impact flywheel operation.

Per the rotor model, the CM mode frequencies do not change with rotor speed. Based on this, the CM mode frequency was set to $85 \mathrm{~Hz}$. This frequency was selected because it is far away from the initial tilt frequency of $30 \mathrm{~Hz}$, and also far from $60 \mathrm{~Hz}$ and its harmonics (which are typically present to some extent as noise in the system), and well below the controller bandwidth. Note that, due to the selection of the higher frequency, the CM stiffness is higher than the tilt stiffness.

Now that the desired $0 \mathrm{rpm} \mathrm{CM}$ and tilt mode frequencies have been selected, the next step is to set them in the system by tuning the $\mathrm{K}_{\mathrm{cm}}$ and $\mathrm{K}_{\text {tilt }}$ gains in the modal controller. This can be done by performing a test similar to the one used to verify modal separation. Once the rotor is levitated on the modal controller and the damping on the mode under test has been decreased, the mode frequency can be observed by watching the underdamped rotor response to a test input square wave signal. Since the mode frequency is proportional to the square root of the mode stiffness (the proportional gain for the mode under test), 0 rpm mode frequencies can be quickly dialed in for each of the modes by iteratively adjusting the appropriate modal controller gain and running the above measurement.

\section{E. Operation of Modal Controller}

The modal controller described above has been implemented and tuned, and has been used regularly to spin the D1 up to its full rated speed of $60 \mathrm{k} \mathrm{rpm}$.

During flywheel operation, the data for position sensors $\mathrm{X} 1, \mathrm{Y} 1, \mathrm{X} 2$, and $\mathrm{Y} 2$ is fed into a spectrum analyzer for analysis. This is helpful, because it allows the operator to monitor, among other things, the status of the rigid body modes. A spectrum of the D1 radial position sensors while operating at $40,000 \mathrm{rpm}$ is presented in figure 11. The synchronous line is at $667 \mathrm{~Hz}$, corresponding to the rotor spin speed. Note that, as expected at this speed, the rigid body modes are all below the synchronous speed. The forward whirl is visible at $500 \mathrm{~Hz}$ (just under the theoretically predicted frequency of $534 \mathrm{~Hz}$ ([Ip/It]*667 Hz), while, as desired, the CM mode has stayed at about $85 \mathrm{~Hz}$, even at this high speed. The BW is not visible on this measurement; the predicted BW frequency is $900 / \mathrm{FW}=1.8 \mathrm{~Hz}$, which is well below the range of the analyzer as configured, but has been verified in other measurements. Note that the $60 \mathrm{~Hz}$ line is visible, along with harmonics at 120 and $180 \mathrm{~Hz}$, as are module housing modes at 15 and $30 \mathrm{~Hz}$.

Using the spectrum analyzer, a map of rigid body mode locations with speed has been generated for the D1 operating range (fig. 12). Note that this figure closely matches the theoretical model presented in figure 8. As expected, the $\mathrm{CM}$ mode starts at about $85 \mathrm{~Hz}$

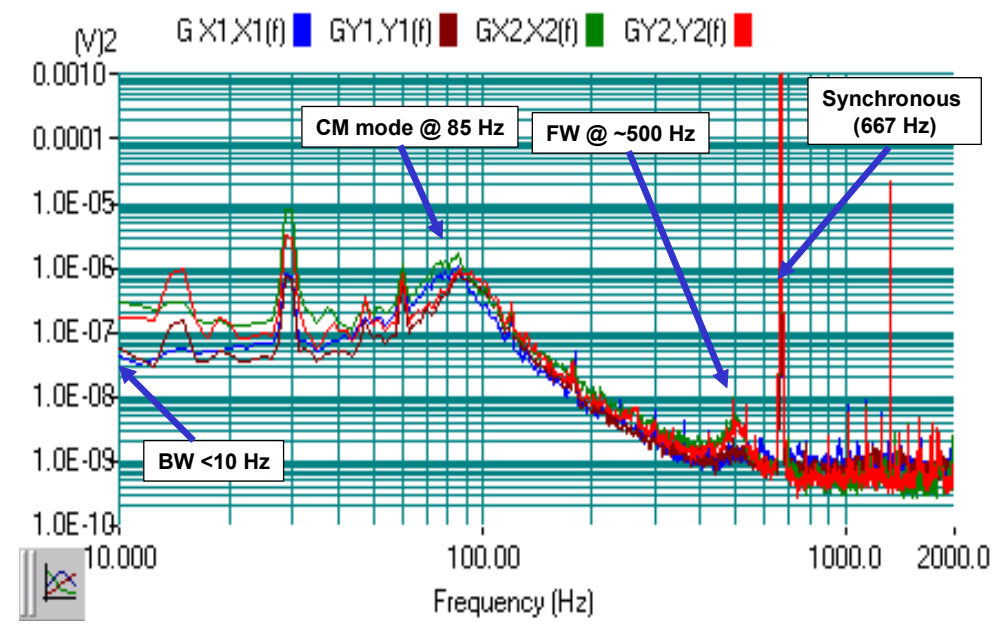

Figure 11.-Spectrum of D1 radial position sensors at $40 \mathrm{k} \mathrm{rpm}$. Rotordynamic Modes

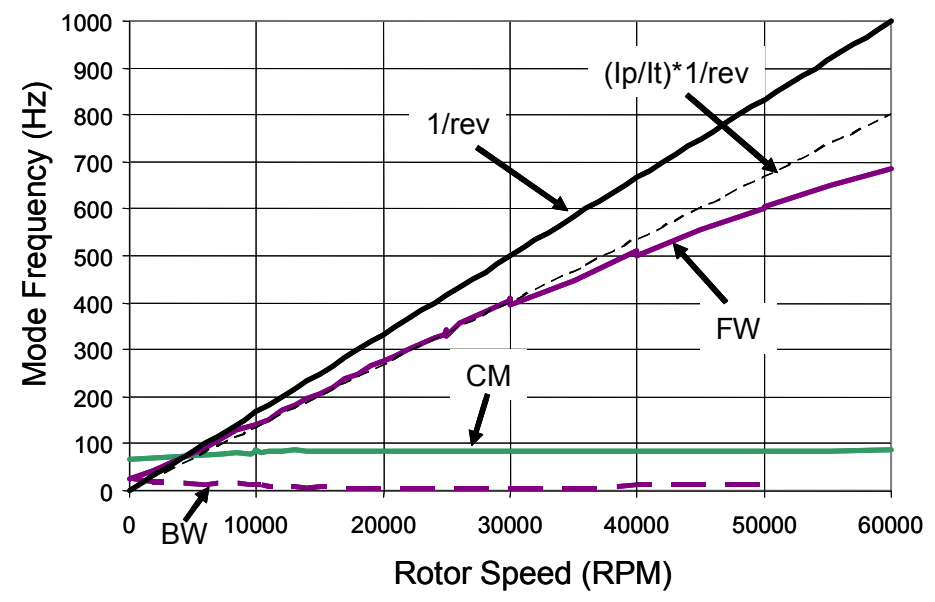

Figure 12.--Measured D1 rigid body modes. 
and moves very little with speed. Also as predicted, the BW mode decreases frequency with speed, and the FW mode starts at $30 \mathrm{~Hz}$ and asymptotes close to the expected $0.8^{*}$ synchronous, or $1 / \mathrm{rev}$, line (the $\mathrm{FW}$ mode deviates from the Ip/It line due to the influence of the first bending mode, as discussed in the next section).

These results demonstrate that, as desired, the modal controller allowed direct control of the natural rotor dynamics (rigid body modes) during flywheel operation. The system modeling effort was successful; the rigid body modes behaved according to the theoretical predictions, and the controller worked as designed. Once other MB controller best practices were incorporated into he controller, such as synchronous notching and rotational noise correction (ref. 2), the controller became capable of regular hands-free control of the rotor from zero speed up to full speed operation.

\section{Rotor Bending Mode Compensation}

The idealized model of the flywheel rotor used in the previous section assumed that the rotor did not bend during flywheel operation (rigid rotor assumption). This assumption is false; real rotors can bend, and proper handling of the rotor bending modes is crucial for safe flywheel operation.

Since real rotors do have bending modes, we would ideally like to design them such that the first bending mode is well above any flywheel operating speed; this would make excitation of the bending modes much less likely, and would make the MB controller design simpler. High bending mode frequencies can be achieved by designing a stiffer rotor; however, a stiffer rotor may be shorter or heavier, which will impact other important system performance specifications. Because of these design tradeoffs, the rotors of the flywheels designed at GRC do have bending modes which are close to, and can sometimes overlap, the rotor synchronous frequency. Excitation of the bending modes during flywheel operation can cause the rotor to resonate at the bending mode frequency, which can have catastrophic results, since the MB actuators cannot control this oscillation. This section describes development of the subsystem used to compensate for the rotor bending modes during operation.

\section{A. Bending Mode Prediction}

At $0 \mathrm{rpm}$, the D1 first and second bending modes are at about 1100 and $1470 \mathrm{~Hz}$. This can easily be verified; by levitation on a poorly tuned d-PD controller, the rotor can be made to resonate at these frequencies. The $0 \mathrm{rpm}$ bending modes are higher in frequency than the top speed of the rotor $(60 \mathrm{k} \mathrm{rpm}=1 \mathrm{kHz})$, however, like the whirl rigid body modes, the bending modes move with frequency. In order to understand bending mode behavior in the D1 flywheel, a theoretical map of bending mode location as a function of flywheel speed was generated.

The first step in generating this map was to develop an FEM model of the D1 rotor. Inputs to the FEM model include the sizes and mechanical properties of each section of the D1 rotor; in addition, a rap test of the rotor was performed, to measure the non-spinning rotor bending mode shapes. A schematic of this FEM model, depicting the excited second bending mode of the D1 rotor, is presented in figure 13).

The completed FEM model was used to simulate the spinning rotor, and map the theoretical D1 bending mode shapes as a function of speed. The theoretical prediction of mode frequencies as a function of rotor speed is shown in figure 14. Note that the model predicts that both the first and second bending modes will split with speed, forming backward and forward bending modes, designated first bending forward whirl (1B FW), first bending backward whirl (1B BW), second bending forward whirl (2B FW) and second bending backward whirl (2B BW).

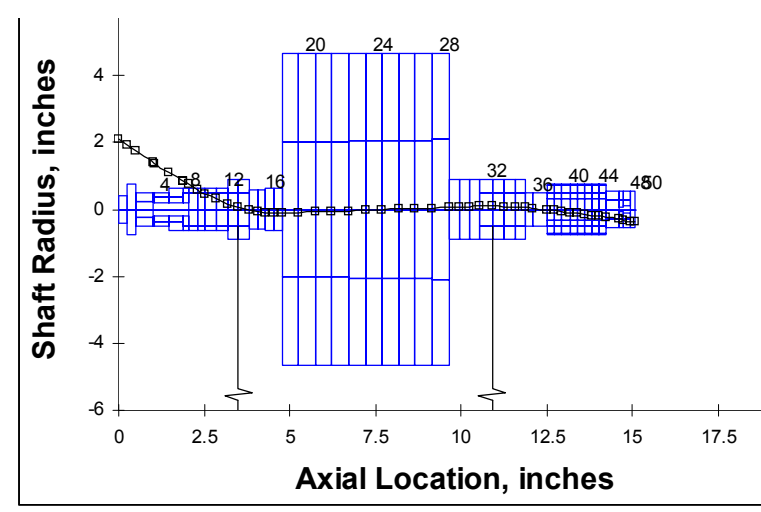

Figure 13.-FEM model of D1 second bending mode. D1 Bending Modes - Prediction

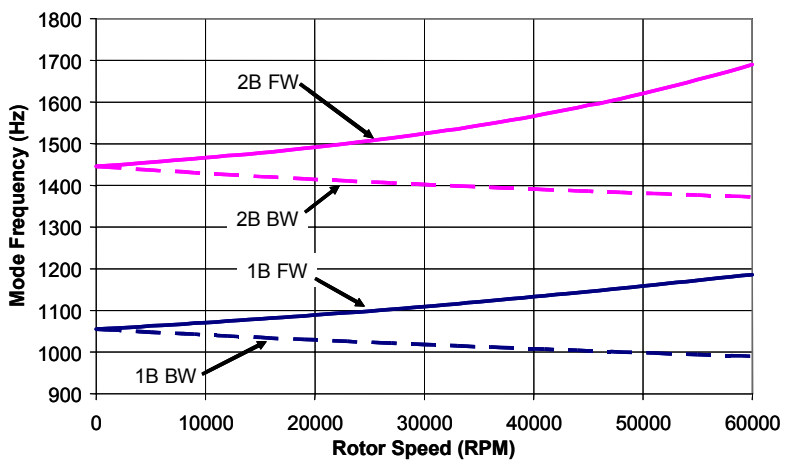

Figure 14.- Map of predicted bending modes. 


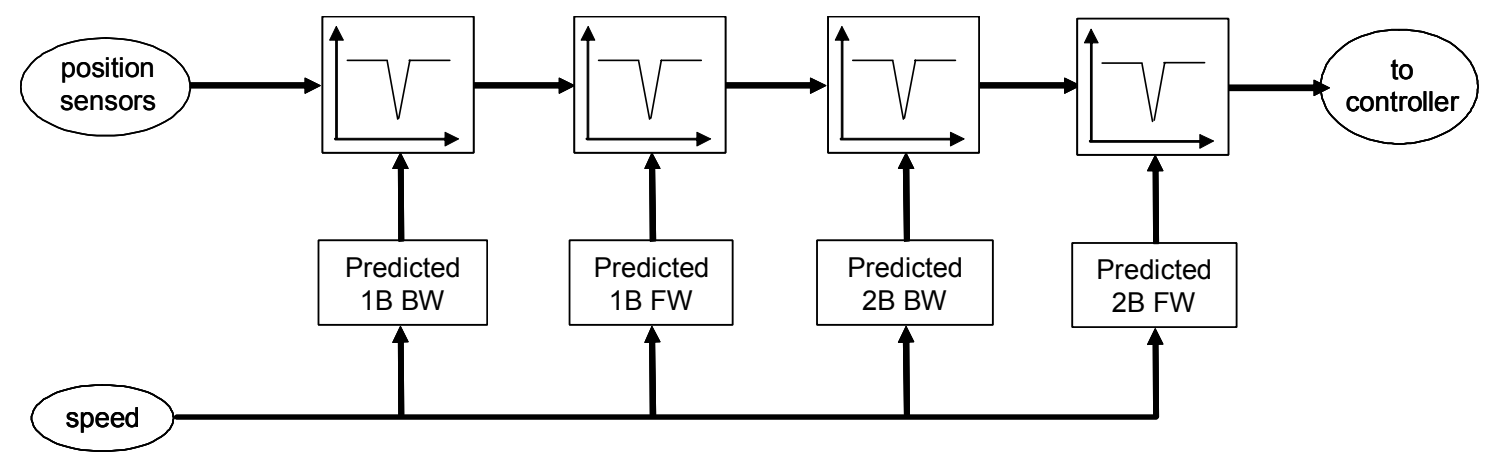

Figure 15.-Bending mode compensation: moving notch filters.

\section{B. Bending Mode Compensation: Moving Notch Filters}

Since the MB actuators can only move the rotor at two points along the shaft, control of bending modes (which resonate along the entire length of the rotor) is impossible with the MB controller. As the excited bending modes cannot be controlled, the controller is designed to simply not excite them. This is done using moving notch filters; these filters prevent any information at the bending mode frequencies from reaching the MB controller, thus preventing any controller output at frequencies which would excite the bending modes. The controller code implementation for these moving bending mode notches is shown in figure 15.

Implementation of the moving notch code was completed as follows: first, a function was fit to the predicted bending mode information, which resulted in functions for all four bending modes versus rotor speed. These functions were then entered into the code, using the rotor speed (as calculated using the OAR sensor, fig. 1) as the input. Predicted bending mode frequencies were then passed on to a set of four daisy-chained digital moving notches. The raw position sensor information is input to this filter set, and the output of the filters, which is passed onto the modal controller, contains the position inputs minus any information at any of the first and second bending modes.

\section{Bending Mode Verification}

In order for the moving notch filters to properly compensate for the rotor bending modes, the predicted locations of the first and second FW and BW bending modes must be accurate, at all operating speeds. In order to fine-tune the theoretical calculations, a verification run was performed, during which the location of all four bending modes was mapped out.

The verification run was done by performing mode location tests while holding flywheel speed constant at regular increments. During a speed hold, the depth of each notch filter under test was gradually decreased, while the position sensor information was carefully monitored on the spectrum analyzer. This process allowed the bending mode to be excited under controlled conditions. Once the bending mode appeared on the spectrum analyzer, its frequency was noted, and the notch filter was placed back to full depth. This process was repeated for all four bending modes, at regular speed increments, during initial high-speed runs on the D1 unit. The actual mapped mode information, along with the initial theoretical predictions, is shown in figure 16. Note that, although there are slight discrepancies, the theoretical data matches the actual bending mode maps very well, predicting the splitting of the modes into forward and backward modes and the general shape of the mode variation with rotor speed.

Note that mode 1B BW is predicted to drop below $1 \mathrm{kHz}$ at full speed $(60 \mathrm{k} \mathrm{rpm})$; this means that operation at speeds near $60 \mathrm{k} \mathrm{rpm}$ could possibly excite this bending mode. However, this has not been a problem, as this mode is difficult to excite at higher speeds. In fact, during mapping effort, we were unable to excite this mode at higher speeds (note missing data beyond

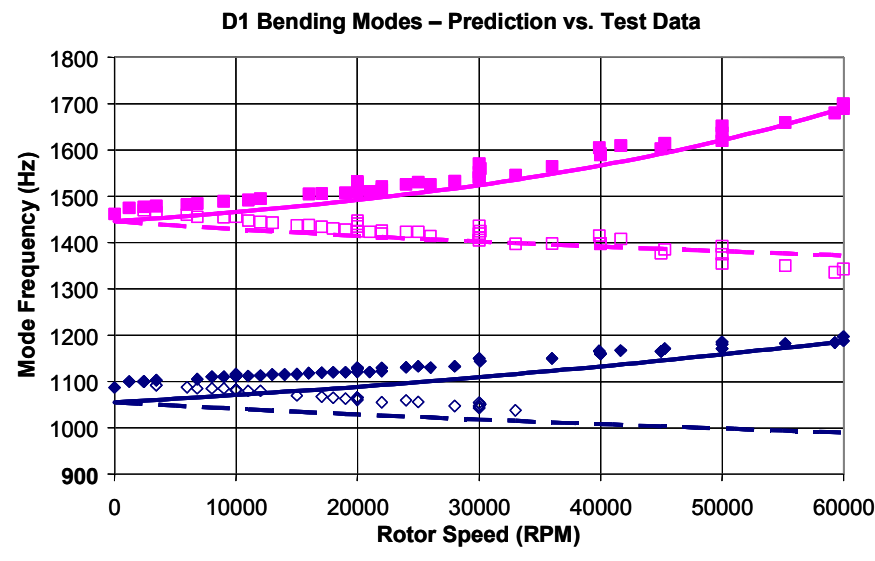

Figure 16.-Predicted and measured bending modes. 
$33 \mathrm{k} \mathrm{rpm}$ for $1 \mathrm{~B} \mathrm{BW}$ in fig. 16). Also, note that the interaction of the FW tilt mode and the $1 \mathrm{~B}$ FW mode is the cause of the FW tilt frequency decreasing below the (Ip/It)*1/rev line at higher speeds (fig. 12).

Information from the bending mode verification run was used to fine-tune the bending mode calculations used in the moving filter set.

\section{Bending Mode Performance-MB Current Spectrum}

As with the input sensor position data (fig. 11), the commanded MB currents are observed on a spectrum analyzer during flywheel operation. This spectrum demonstrates the operation of the bending mode filters. A sample MB current spectrum is shown in figure 17;

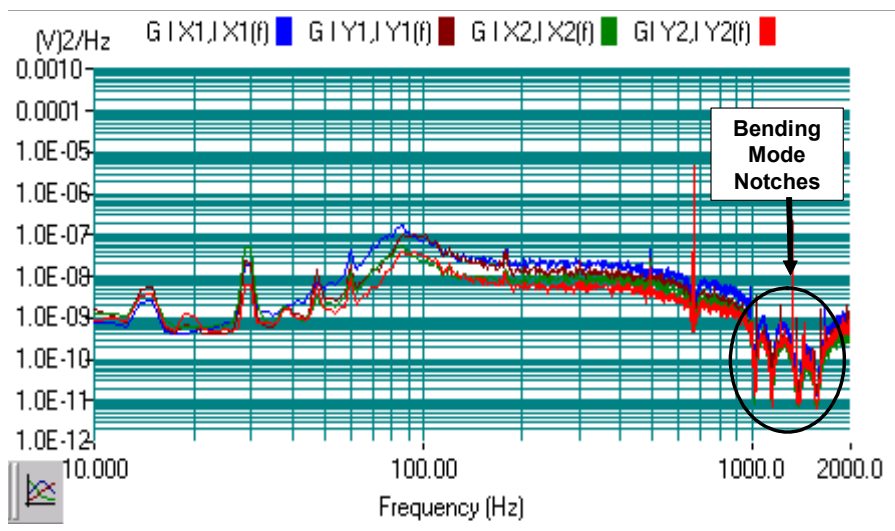

Figure 17.- Predicted and measured bending modes. this plot shows the commanded currents while the D1 is levitated and spinning at $40 \mathrm{k} \mathrm{rpm}$. Operation of the notch filters can be seen in the current information above $1 \mathrm{kHz}$; the controller has prevented any output current (and thus excitation) at the locations of the 1B BW, 1B FW, 2B BW, and 2B FW modes. Preventing controller output at the bending mode frequencies has prevented any excitation of the bending modes during D1 operation to full speed.

\section{Conclusions}

The goals of the magnetic bearing controller modeling and design effort, as presented in the Problem Statement, have been successfully met. Models were developed for the overall system, the rotor rigid body modes and the rotor bending modes, then successfully validated and incorporated into the final controller design. Modeling of the rotor rigid body behavior allowed development of the modal controller, which allows direct control of the flywheel rotor rigid body modes (rotordynamics). The structure of the controller, designed with a setup file with variables left as measurable values, makes it generic and portable to new flywheel modules. Data taken on the D1 flywheel module during high speed operation demonstrates successful operation of the MB controller.

\section{References}

1. Vance, J.M., Rotordynamics of Turbomachinery, Texas A\&M University, College Station, Texas, 1988, Chapter 4.

2. Dever, T.P., et al., "Magnetic Bearing Controller Improvements for High Speed Flywheel System," August 2003 IECEC Conference Proceedings, Portsmouth, VA, 2003. 


\begin{tabular}{|c|c|c|c|}
\hline \multicolumn{3}{|c|}{ REPORT DOCUMENTATION PAGE } & $\begin{array}{l}\text { Form Approved } \\
\text { OMB No. 0704-0188 }\end{array}$ \\
\hline \multicolumn{4}{|c|}{ 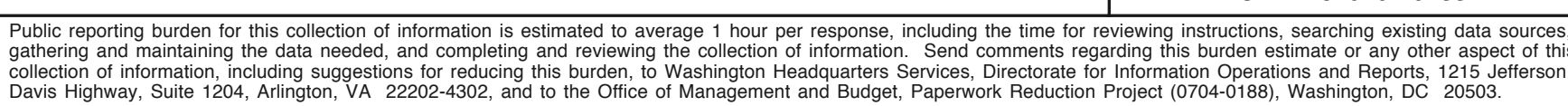 } \\
\hline 1. AGENCY USE ONLY (Leave blank) & $\begin{array}{l}\text { 2. REPORT DATE } \\
\text { September } 2005\end{array}$ & $\begin{array}{r}\text { 3. REPORT TYPE AI } \\
\mathrm{T}\end{array}$ & $\begin{array}{l}\text { D DATES COVERED } \\
\text { echnical Memorandum }\end{array}$ \\
\hline \multicolumn{3}{|c|}{$\begin{array}{l}\text { 4. TITLE AND SUBTITLE } \\
\text { Modeling and Development of a Magnetic Bearing Controller for a High Speed } \\
\text { Flywheel System }\end{array}$} & 5. FUNDING NUMBERS \\
\hline \multicolumn{3}{|c|}{$\begin{array}{l}\text { 6. AUTHOR(S) } \\
\text { Timothy P. Dever, Gerald V. Brown, Kirsten P. Duffy, and Ralph H. Jansen }\end{array}$} & WBS-22-319-20-M1 \\
\hline \multicolumn{3}{|c|}{$\begin{array}{l}\text { 7. PERFORMING ORGANIZATION NAME(S) AND ADDRESS(ES) } \\
\text { National Aeronautics and Space Administration } \\
\text { John H. Glenn Research Center at Lewis Field } \\
\text { Cleveland, Ohio } 44135-3191\end{array}$} & $\begin{array}{l}\text { 8. PERFORMING ORGANIZATION } \\
\text { REPORT NUMBER }\end{array}$ \\
\hline \multicolumn{3}{|c|}{$\begin{array}{l}\text { 9. SPONSORING/MONITORING AGENCY NAME(S) AND ADDF } \\
\text { National Aeronautics and Space Administration } \\
\text { Washington, DC } 20546-0001\end{array}$} & $\begin{array}{l}\text { 10. SPONSORING/MONITORING } \\
\text { AGENCY REPORT NUMBER } \\
\text { NASA TM-2005-213877 } \\
\text { AIAA-2004-5626 }\end{array}$ \\
\hline \multicolumn{4}{|c|}{$\begin{array}{l}\text { 11. SUPPLEMENTARY NOTES } \\
\text { Prepared for the Second International Energy Conversion Engineering Conference sponsored by the American Institute } \\
\text { of Aeronautics and Astronautics, Providence, Rhode Island, August 16-19, 2004. Timothy P. Dever, QSS Group, Inc., } \\
21000 \text { Brookpark Road, Cleveland, Ohio 44135; Gerald V. Brown, NASA Glenn Research Center; and Kirsten P. Duffy } \\
\text { and Ralph H. Jansen, University of Toledo, } 2801 \text { W. Bancroft Street, Toledo, Ohio 43606. Responsible person, Timothy } \\
\text { P. Dever, organization code DR, 216-433-2384. }\end{array}$} \\
\hline \multicolumn{3}{|c|}{$\begin{array}{l}\text { 12a. DISTRIBUTION/AVAILABILITY STATEMENT } \\
\text { Unclassified - Unlimited } \\
\text { Subject Categories: } 20 \text { and } 44 \\
\text { Available electronically at http://gltrs.grc.nasa.gov } \\
\text { This publication is available from the NASA Center for AeroSpace Information, 301-621-0390. }\end{array}$} & 12b. DISTRIBUTION CODE \\
\hline
\end{tabular}

This paper describes a modeling effort used to develop an improved type of magnetic bearing controller, called a modal controller, for use on high speed flywheel systems. The controller design is based on models of the flywheel system, is designed to directly control the natural dynamics of the spinning rotor, and is generic enough to be readily adapted to future flywheel systems. Modeling and development are described for two key controller subsystems: the modal controller subsystem, which allows direct control over the rotor rigid body modes, and the bending mode compensation subsystem, which tracks, and prevents interference from, the rotor bending modes during flywheel operation. Integration of modeling results into the final controller is described and data taken on the NASA Glenn D1 flywheel module during high speed operation are presented and discussed. The improved modal controller described in this paper has been successfully developed and implemented and has been used for regular hands-free operation of the D1 flywheel module up to its maximum operating speed of 60,000 RPM.

\begin{tabular}{|c|c|c|c|}
\hline \multicolumn{3}{|l|}{ 14. SUBJECT TERMS } & 15. NUMBER OF PAGES \\
\hline \multicolumn{3}{|c|}{ Flywheel; Magnetic bearing; Controller } & 18 \\
\hline $\begin{array}{l}\text { 17. SECURITY CLASSIFICATION } \\
\text { OF REPORT }\end{array}$ & $\begin{array}{l}\text { 18. SECURITY CLASSIFICATION } \\
\text { OF THIS PAGE }\end{array}$ & $\begin{array}{l}\text { 19. SECURITY CLASSIFICATION } \\
\text { OF ABSTRACT }\end{array}$ & 20. LIMITATION OF ABSTRACT \\
\hline Unclassified & Unclassified & Unclassified & \\
\hline
\end{tabular}



